\title{
BRAIN. Broad Research in Artificial Intelligence and Neuroscience
}

ISSN: 2068-0473 | e-ISSN: 2067-3957

Covered in: Web of Science (WOS); PubMed.gov; IndexCopernicus; The Linguist List; Google Academic; Ulrichs; getClTED; Genamics JournalSeek; J-Gate; SHERPA/ROMEO; Dayang Journal System; Public Knowledge Project; BIUM; NewJour; ArticleReach Direct; Link+; CSB; CiteSeerX; Socolar; KVK; WorldCat; CrossRef; Ideas RePeC; Econpapers; Socionet.

2020, Volume 11, Issue 3, Sup.1, pages: 127-136 I

https://doi.org/10.18662/brain/11.3Supl/128

\section{A Tale of Two Frontal Lobes. Clinical \\ Perspectives of Cortical}

\section{Interconnectivity}

\author{
Alina - Ioana VOINEA ${ }^{1 *}$, \\ Mirona Letitia DOBRI' \\ Codrina MORARU ${ }^{3}$, \\ Petronela NECHITA ${ }^{4}$, \\ Anamaria CIUBARA ${ }^{5}$
}

${ }^{1}$ LAS CT, Hertfordshire Partnership University NHS Foundation Trust, St. Albans, United Kingdom, alina ioana92@yahoo.com

${ }^{2}$ IIIrd Year Psychiatry Resident, "Socola" Institute of Psychiatry, Iasi, Romania

${ }^{3}$ IInd Year Psychiatry Resident, "Socola" Institute of Psychiatry, Iasi, Romania

${ }^{4} \mathrm{MD}, \mathrm{PhD}$, Senior Psychiatrist, "Socola" Institute of Psychiatry, Iasi, Romania ${ }^{5} \mathrm{MD}, \mathrm{PhD}$, Professor of Psychiatry, "Dunarea de Jos" University, Galati, Romania
Abstract: Even through centuries passed, while neurosciences were mistaken only for phrenology, and neuronal mapping did not exist as a self-sustained science, structural changes of the brain were associated, at various degrees, with reoccurring activities or behavioural patterns of the patient. An extraordinary neuroplasticity was therefore described, meant to complete the cerebral network, which sustained superior cognitive functioning and played an essential role in adapting to the environment. Most of this web of electrical impulses has its nodes inside the frontal system, in such a way that no one lobe can be identical to another, structurally or when considering informational content. Cortical interconnectivity observed in frontal lobes may be a measure of physiological variety, but also an aid in understanding linked psychopathology.

The first case we will focus our attention on is Phineas Gage, the railway worker who marked the history of neuroscience through his bizarre accident and unexpected outcome. Beyond the myth, this famous patient amended the understanding of the brain's organization and revolutionized functional cerebral mapping. From here on, we will follow the evolution of neuronal connectivity studies and their implications in psychiatric pathology, as they are known today. Neuroimaging studies on obsessive compulsive disorders, cerebral lesions masked by different psychiatric phenomena, as well as correlations between certain affected tracts and symptoms of psychotic disturbances, are all scientific events which may offer new directions in clinical psychopathology and can invoke different therapeutic resources.

In conclusion, to follow studies of neuronal mapping and use the understanding we already have, might be the answer to more complex case management, improving a patient's outcome and helping us choose treatment plans more effectively. As a story unfolding from two opposing perspectives, the science behind cortical interconnectivity stands witness to different principles acting in conjunction for better results, should one only use it.

Keywords: frontal systems; neuronal interconnectivity; cortical mapping; clinical psychopathology.

How to cite: Voinea, A.-I., Dobri, M.L., Moraru, C., Nechita, P., \& Ciubara, A. (2020). A Tale of Two Frontal Lobes.

Clinical Perspectives of Cortical Interconnectivity. BRAIN. Broad Research in Artificial Intelligence and Neuroscience, 11(3), 127136. https://doi.org/10.18662/brain/11.3Sup1/128 


\section{Main Character - The Frontal Lobe System}

The genius of Italian Renaissance artist Michelangelo Buonarroti remains one of the essential topics of the history of art. Alongside da Vinci, he is elementary to the discovery of the human mind, as we now know it. He painted magnificent frescoes on the ceiling of the Vatican's Sistine Chapel, laboring from 1508 to 1512. Commissioned by Pope Julius II, Michelangelo performed this work himself, without assistance, and revealed the grandiose layout in its entirety, withstanding the pressure of christian figures of importance during those 4 years. Scholars debate whether he had any guidance from the Church in the selection of the scenes, and what meaning the scenes were to convey. Neuroscientists though, have proclaimed over time numerous findings of absolute importance in those images. In the fresco traditionally called the „Creation of Adam”, but which might be more aptly titled the Endowment of Adam, Michelangelo encoded a hidden message. It is a message consistent with thoughts he expressed in his sonnets. Supreme in sculpture and painting, he understood that his skill was in his brain and not in his hands. He believed that the "divine part" we "receive" from God is the "intellect", this bringing with itself a power higher than any other could be.

Below God's hand pointing towards Adam, the pink cloak has a fold that may be recognized as the Sylvian fissure as shown in the pictures above. Similarly, following anticlockwise, the cherub's knee assumes the shape of the optic chiasm and the back of the angel below God takes the shape of the pons. The sulcus cinguli extends along the hip of the angel in front of God, across his shoulders and over Eve's forehead. The flowing green textured robe stand in place for the vertebral artery, in it's rapport to the spinal cord as represented by the intertwined legs. The pituitary stalk and gland are depicted by the foot of the angel that go beyond the base of the picture.

Most importantly thoug, is not to identify detailed neuroanatomical structures, but better yet to understand the larger image of the Creator as being compatible with cognitive and high functioning commands yielded by the cerebral cortex. God gives to Adam, a mere mortal, the power of knowing and learning the world around him, and by spearing with his hand the prefrontal area of the brain, he endowes Adam with personality and archetypal traits (Meshberger, 1990).

Beyond all neuroscientific stories (Bamijoko-Okungbaye, 2018; Sandu, 2017), the frontal lobe is one of the most important anatomical areas of the brain, in dimensions as well as in functionality. It is considered the 
largest, macroscopically, the cortical layer of the lobe accounting for approximately $37-39 \%$ of the cerebral cortex, where part of this structure is composed of the prefrontal cortex (PFC). This cortical region forms part of an extensive connective network involved in socioemotional abilities and in the executive function of humans and other primates.

Comparative studies suggest that the characteristic differentiation of the prefrontal lobe of humans compared to that of other primates lies more in circuit organization than mere size of the structure. From a phylogenetic perspective, it is believed that the relatively recent reorganization of the frontal cortical circuitry has been pivotal to the emergence of the specific cognitive functions of the frontal lobe in humans (Burlea et al., 2010).

\section{Functionality of the Highest Importance}

At a first glance towards indepth anatomy of the brain, the prefrontal areas are devouted to specific functionalities. The higher cognitive expressions are linked moreso to the dorsolateral parts of the frontal lobe (Broadmann 9, 10, 4), while social abilities are related to the orbitofrontal cortex within Broadmann areas 10, 11, 13, 47 (João \& Filgueiras, 2018).

Few distinctive circuits are considered of major significance throughout the frontal gray matter, mainly the dorsolateral circuit, orbitofrontal circuit, and the circuit including the front cingulate parcels of the frontal projection. These connective pathways begin and end within the prefrontal cortex, whereas their direction can extend them to particular structures, such as the caudate, globus pallidus, thalamus, and other neocortical areas. The dorsolateral circuit (DLC) fundamentally advances organizational capacity and decision weighing.

Taking the clinicians stand, harm to these pathways can cause hyperperseveration, diminished capacity for deliberation, lack of moral and social etiquette, disabled verbal output, and destitute execution on complex figure replicating. According to Burruss et al., Brodmann areas 9 and 10 contain neuron cellular bodies that correspond to the start and end of the dorsolateral circuitry. The neurons of this region project to the dorsolateral portion of the caudate nucleus, from which juncture they develop direct and indirect pathways which appear to have a reciprocal modulation mechanism via excitatory and inhibitory stimuli.

With respect to the orbitofrontal circuit, it takes on the work of balancing satisfactory social behavior and is principal for keeping up sympathy. Disturbances within the pathways of this framework lead to certain neuropsychiatric admittances such as impulsivity, passionate lability, 
shifts in personality, unstable behavioral tendencies, and need of interpersonal affectability. Like the dorsolateral circuit, the orbitofrontal begins in the tenth and eleventh Brodmann regions. Their axons project to the ventromedial parcel of the caudate nuclei, where they veer into a direct and an indirect path.

The coordinate pathway enters the dorsomedial globus pallidus and the medial rostral area of the pars reticulata, where they proceed to the anterior parcel of the thalamus, after which coming back to the prefrontal. The circuitous pathway of the orbitofrontal circuit enters a feedback loop by connecting to the dorsal part of the external globus pallidus and to the sidelong subthalamic nucleus. The indirect track of the orbitofrontal regulates the direct one through the association to the dorsal part of the external globus pallidus and the horizontal subthalamic core. Both pathways go up next to each other next to dorsolateral circuitry (Mega \& Cummings, 1994).

Remotely to this, the horizontal parcel of the orbitofrontal inputs afferences primarily from the temporal grey matter, the amygdala, and ventral tegmental region. Thus, the associations to the distal collateral ranges are also complementary, as it happens with comparative integrator pathways within the dorsolateral circuits.

The anterior cingulate and its connections control incentive by tweaking downregulated input within the supplemental motor zone, using its own signals for keeping up the awake and alert state. The foremost apparent shortfalls of stops in the circuitry arranged within the prefrontal cortex are related with respective injuries of the front cingulate, the clinical signs being akinetic mutism, lack of concern, abulia, and no response to sensorial stimulation.

\section{Business Enough}

Phineas Gage, a seemingly healthy man aged 25 was a head railroad worker coordinating others who were building the train line from Rutland to Burlington in the United States of America. They were handling the clearing and leveling of the landscape when the gruesome mischance took place, on the 13th of September 1848, close to Cavendish. As they had done numerous times until then, Gage made a hole in the stone and packed gunpowder inside of it with a tamping iron. This is exactly the rod you can see in the picture next to this paragraph, as by mistake an explosion was caused by the friction inside the rock and the metallic object hit Phineas in the head. It passed through his left hemifacies and penetrated the front side 
of his skull. He was urgently taken to a hotel in the city by his coworkers, at which point he was fully conscious and able to move without support of any kind. He retold the mindboggling story of the accident to Edward Higginson Williams, the first doctor to see him, and greeted him by way of: „Doctor, here is business enough for you".

Under Dr John Martyn Harlow's attentive medical care, Gage was able to survive his injuries. What needed to be done firstly was to stop the massive haemorrhage and remove the remaining bone fragments from the affected area. In addition, by elevating Gage's head, Harlow allowed drainage at the sight of the wound. In the weeks after, the primary course of action was to treat the infection that followed the accident. Based on 19th century medical beliefs, Harlow made use of colchicum and mercury chloride for their cathartic properties as he tried to stop the inflammatory process from progressing. Almost 3 months afterwards, Phineas Gage's physical state had improved significantly and he was declared cured.

Two decades from the accident, dr Harlow managed to rebuild the chronology of what happened to his stellar patient between the fateful spring of 1849 and his demise. Following statements from his mother, it seemed that Gage had moved and found work in Chile for a long time, but eventually returned to his birthplace, where he ended up dying after a string of previously undiagnosed tonico-clonic convulsions and their complications.

In November 1848, the same clinician that had helped Gage at the time of his impressive accident wrote a letter for the Boston Medical and Surgical Journal in which he described everything that happened and the medical challenges overcome. What followed after, as far as behavior and personality disorders go, was highlighted through a presentation entitles "Recovery from the passage of an iron bar through the head"made by $\mathrm{dr}$ Harlow in front of the Massachusetts Medical Society", in 1868: "The balance between his intellectual faculties and animal propensities, seems to have been destroyed. He is fitful, irreverent, indulging at times in the grossest profanity (...), manifesting but little deference for his fellows, impatient of restraint of advice when it conflicts with his desires, at times pertinaciously obstinate, yet capricious and vacillating, devising many plans of future operation, which are no sooner arranged than they are abandoned in turn for others appearing more feasible" (Harlow, 1868).

In the years of Phineas Gage's sustained wound, the brain was though to be a homogenous jelly-like substance with no specific capabilities. This have only later and gradually shifted, as advances in the understanding of functionality and anatomy of the cortex were made at quite a fast pace. 
Paul Broca was one of the most prominent scholars with an avid interest in this topic, and he wrote his contribution in 1861, when he put brain areas and their targeted function under the limelight. His anatomy focused studies were carried on two patients with loss of verbal acuity and expressivity, and it was demonstrated this was in connection to injuries sustained of the left frontal lobe, on the third ridge. The link between cognitive exercise and a specific cerebral region was thereafter widely accepted and acknowledged by the scientific community.

David Ferrier was one of the frontrunners studying cortical localisation fo function. He managed to draw a precise motor and sensory map of the cortical processes through the removal of some cerebral tissues and by using alternate electricity as stimulus. At the same time, Ferrier surgically extirpated a substantial part of the prefrontal cortex of 3 monkeys. Not even a single one presented with changes in their motricity, sensory or perceptual process (Bolos et al., 2012; MacFall et al., 2001). The story of how neuroscience began to delevop starts therefore in the functional consequences of frontal cortex injury, as Phineas Gage and his medical revolution shows.

\section{The Frontal Lobe Amidst Psychotic Symptoms}

An essential symptom of schizophrenia is represented, as we all know, by the delusions and hallucinations progressively lowering an individual's quality of life. This is a form of functional mishap of the frontal cortex which, according to recent studies, has been negatively correlated with the gray matter volume of the lobe. The decreased dopamine release activation in the dorsal and lateral prefrontal part has been noted in connection to this (Chirita et al., 2012).

The behavioral pattern this lobe is heavily involved in is that of suicidal ideation, which is a severe symptom of psychotic disturbances and can be unequivocally attributed to the dysfunctionality of prefrontal circuitry. Patients suffering from this perceptual disorder have decreased controlling feedback in their premotor cortex, and lowered response to goaldriven actions in multiple areas, but usually on the same side with the primary motor cortex.

Fractional anisotropy is another guidance in schizophrenic symptoms' correlation to functional neuroanatomy. This is reduced in the left anteromedial orbitofrontal cortex, anterior cingulate and bilateral 
posterior projections. Higher percentages of abulia, apathy or anhedonia were seen in cases with changes in the left posterior cortical connections.

A smaller volume of grey matter in the prefrontal region has been shown to relate to impaired advanced functioning and the duration of the disorder has a direct proportionality relationship to the area modified. With this comes a lowered metacognitive insight as well as changes to the putamen, insula, the left ventrolateral prefrontal and right dorsal prefrontal cortex. The white matter fasciculi suffer shifts as well, being decreased in volume as well, especially in the corona radiata, forceps minor and superior longitudinal pathways. On the cellular level, schizophrenia leads to a smaller number of spinal radiations and shorter length of each dendrite. At the same time there appears a turnover of pericapillary oligodendrocytes in the prefrontal cortex of patients, which might as well highlight new study directions in the pathophysiology of neuronal psychotic disturbances.

In recent years, neuroscientists have tried various ways of focusing on the connections between executive functionality and psychosis in the detailed cortical sense, and so made use of any means possible to understand the disturbances found (Mubarik \& Tohid, 2016). For example, using a technique called BOLD RM (blood oxygen level dependent), it was noted that the blood supply to the prefrontal cortex in schizophrenic patients is significantly lower than in healthy controls, with OxyHB standing proof to the progression of illness. This has a positive proportionality relation to the degree in severity of the psychotic symptoms and shows a greater measure of hypofrontality (Lim et al., 1999).

\section{Loss of Control Mirrored by the Frontal Systems}

Even in the 19th century reports were given that frontal lobe injuries could lead to an acute onset of antisocial traits in the patient, being associated with impulsivity, explosive outbursts, inappropriate actions or verbal cues, while the basic functioning of cognition, and motricity remain relatively spared. In adult age there was a term coined for individuals suffering from prefrontal lesions - ,acquired sociopathy” - showcasing a minimum of impaired executive functionality but important inability towards palpable tasks requiring judgement calls, being morally and socially aware and having the capacity to predict outcomes before taking actions (O'Driscoll \& Leach, 1998). In almost the same manner, patients who suffered frontal circuitry damage at a young age, report recurrences of impulsivity, aggresiveness and comitting antisocial acts, as well as a dysfunctionality of primary cognitive functions, poor abstract or 
conceptualized thinking, lacking in empathy and moral naivety to a variable extent upon reaching adulthood.

Frontal abnormal findings were brought up by both the morphometric and brain imaging studies of impulsive individuals. One study focusing on volumetry on MRI brain scans compared an antisocial behavior individuals group with substance abusers, psychiatric and healthy control groups. The most important differences could be structured into three tiers: more aggressive antisocial actions, better highlighted psychopathic traits, and low overall prefrontal grey matter volume (Goghari et al., 2015). These were much more accentuated in the antisocial personality disorder group than in any of the others. With regards to the substance misusers, it was shown that alcohol dependent subjects who also displayed personality traits of abuse and impulsivity had comparatively greater frontal hypoperfusion than those with no antisocial tendencies (Haukvik et al., 2013).

Forensic patients were paralleled to a healthy control group throughout a number ot PET brain scan studies. The positron emission tomography showed a decrease in the bloodflow and metabolic reactions brought on by thoughtless abusive behaviors repeated a number of times. The lower anteromedial and left orbitofrontal metabolism in individuals with personality disorders such as narcissistic or border, was connected to higher levels of aggressive actions using standardized scales (Slifstein et al., 2015).

When evaluating violent patients, the neuropsychiatrist should pay attention to the clinical findings on frontal lobe impairment and assesing of their high executive functionality, especially when the situation surrounds a pattern of recurrent impulsivity and abuse. In order to advance in this field of study, need arises for a multidisciplinary approach that can bring together psychological techniques, neurology issues, and physiological changes for the in depth understanding of localised functionality of the brain, especially in areas such as emotion processing, social adaptability and higher cognitive capabilities.

\section{Conclusions}

The human brain was built indeed to tell stories. What kind of stories, and for how long will we go on without understanding them is anyone's question. If one sits still enough, one can decipher the going ons inside their mind. This is a precious but fleeting sensation we should struggle to explain more clearly. 
As psychiatrists we are indebted to the world of neurosciences and obliged to measure our strength in front of technologically advanced systems that can guide us and bring us valuable information on the state of functionality of the cerebral cortex. CT scans, MRI with added BOLD contrast techniques, tractography, are but a few of the widely used tools that aid us in gathering pivotal data to research the mind wavelength.

In keeping up with advancements in the field, while understanding where we came from, we explore innovative trajectories that not only shade new light on cognitive functionality, but improve outcomes in the clinical setting. Whether we try to understand the phase of the psychotic narrative our patient finds himself in, or adjust medications accordingly to the state of receptoral disponibility, imaging techniques and metabolic measurements are the new musts for a better quality of life.

\section{References}

Bamijoko-Okungbaye, A. (2018). Neuroimaging and the limits of brain imaging techniques. Postmodern Openings, 9(3), 64-75.

https://doi.org/10.18662/po/36

Bolos, A., Ciubara, A-M, \& Chirita, R. (2012). Moral And Ethical Aspects Of The Relationship Between Depression And Suicide. Revista Romana De Bioetica, 10(3), 71-79.

Burlea, G., Burlea, A. M., \& Milici, R. C. (2010). Prevention and intervention in speech and language therapy for the success of lexicographical acquisitions. Revista de Cercetare si Interventie Sociala, 30, 86-100. https://www.rcis.ro/images/documente/rcis30 07.pdf

Chirita, R, Sacuiu, I, Burlea, A, \& Chirita, V. (2012). The role of nitric oxide inhibitors in treatment on symptom severity and cognitive deficits in schizophrenia. International Journal Of Neuropsychopharmacology,15,113-113.

Goghari, V. M. Truong, W., \& Spilka, M. J. (2015). A magnetic resonance imaging family study of cortical thickness in schizophrenia. American Journal of Medical Genetics, 168, 660-668. https://doi.org/10.1002/ajmg.b.32354

Harlow, J. M. (1868). Recovery from the passage of an iron bar through the head. Publications of the Massachusetts Medical Society, 2(3). Reprinted by David Clapp \& Son, 1869. 22 pages.

Haukvik, U. K., Hartberg, C. B., \& Agartz, I. (2013). Schizophrenia--what does structural MRI show? Tidssker Nor Laegeforen, 133, 850-853.

https://doi.org10.4045/tidsskr.12.1084

João, R. \& Filgueiras, R. (2018). Frontal Lobe: Functional Neuroanatomy of Its Circuitry and Related Disconnection Syndromes, Prefrontal Cortex, 41. In 
Starcevic, A., \& Filipovic, B. (Eds.), Prefrontal Cortex. IntechOpen. https://doi.org/10.5772/intechopen.79571

Lim, K. O., Hedehus, M., Moseley, M., deCrespigny, A., Sullivan, E. V., Pfefferbaum A. (1999). Compromised white matter tract integrity in schizophrenia inferred from diffusion tensor imaging. Archives Of General Psychiatry, 56(4), 367-374. https://doi.org/10.1001/archpsyc.56.4.367

MacFall, J. R., Payne, M. E., Provenzale, J. E., \& Krishnan, K. R. (2001). Medialorbital frontal lesions in late-onset depression. Biological Psychiatry, 49(9), 803-806. https://doi.org/10.1016/s0006-3223(00)01113-6

Mega, M. S., \& Cummings, J. L. (1994). Frontal-subcortical circuits and neuropsychiatric disorders. The Journal of Neuropsychiatry and Clinical Neurosciences, 6(4), 358-370. https://doi.org/10.1176/jnp.6.4.358

Meshberger, F. L. (1990). An Interpretation of Michelangelo's Creation of Adam Based on Neuroanatomy. JAMA, 264(14), 1837-1841. https://doi.org/10.1001/jama.1990.03450140059034

Mubarik, A., \& Tohid, H. (2016). Frontal lobe alterations in schizophrenia: a review. Trends Psychiatry Psychother, 38(4), 198-206. https://doi.org/10.1590/2237-6089-2015-0088

O'Driscoll, K., \& Leach, J. P. (1998). "No longer Gage": an iron bar through the head. Early observations of personality change after injury to the prefrontal cortex. BMJ, 317(7174), 1673-1674. https://doi.org/10.1136/bmj.317.7174.1673a

Sandu, A. (2017). Neurological programming techniques (NLP). Suggestions for practice. Moldavian Journal for Education and Social Psychology, 1(1), 41-45. https://doi.org/10.18662/mjesp/2017.0101.05

Slifstein, M., van de Giessen, E., Van Snellenberg, J., Thompson, J. L., Narendran, R., Gil, R., Hackett, E., Girgis, R., Ojeil, N., Moore, H., D'Souza, D., Malison, R. T., Huang, Y., Lim, K., Nabulsi, N., Carson, R. E., Lieberman, J. A., \& Abi-Dargham, A. (2015). Deficits in prefrontal cortical and extrastriatal dopamine release in schizophrenia: a positron emission tomographic functional magnetic resonance imaging study. $J A M A$ psychiatry, 72(4), 316-324.

https://doi.org/10.1001/jamapsychiatry.2014.2414 